\title{
Batı Karadeniz Havzasının Yağış Verilerinin Yenilikçi Şen Yöntemi İle Analizi
}

\author{
Gökmen ÇERIBASŞI
}

Sakarya Üniversitesi, Teknoloji Fakültesi, İnşaat Mühendisliği Bölümü, 54187, Sakarya, Türkiye, gceribasi@ sakarya.edu.tr,

Son y1llarda, Türkiye'nin iklim özelliklerinde belirgin bir değişim izlenmektedir. Küresel iklim değiş̧ikliği genel trendi ile uyumluluk gösteren bu değişiklikler Batı Karadeniz Havzası'nda da kendini hissettirmektedir. Küresel iklim değişikliğinin en büyük etkilerinden biri yăğşlar üzerinde meydana gelip; bu durum bazı bölgelerde yağış azlığı nedeniyle kuraklığa neden olurken; bazı bölgelerde ise ekstrem yağışlar sonucu sel ve taşkınlar şeklinde kendini göstermektedir. Bu çalışmada da iklim değişikliğinin Batı Karadeniz Havzasında etkisi yenilikçi şen yöntemi ile araştırılmıştır. Yenilikçi Şen Yöntemi, bu havzada bulunan meteorolojik istasyonlardan alınan yağış verilerine uygulanmıştır. Bu yağış verileri Devlet Meteoroloji İşleri Genel Müdürlüğ̈̈nden alınmıştır. Yapılan çalışma sonucunda, bazı istasyonlarda trend görülmezken bazı istasyonlarda azalan trendler görülmüştür. Bu azalan trend sonucu da ileride yağışların azalacağı sonucunu ortaya koymuştur.

Anahtar Kelimeler: Yağ̣ş̧, İklim Değişikliği, Batı Karadeniz Havzası, Yenilikçi Şen Yöntemi

\section{Analysis of Rainfall Datas of the West Black Sea Basin by Innovative Sen Method}

\author{
Gökmen ÇERİBAŞI
}

\begin{abstract}
Sakarya University, Faculty of Technology, Department Of Civil Engineering, 54187, Sakarya, Turkey,
\end{abstract} gceribasi@sakarya.edu.tr

\begin{abstract}
In recent years, significant changes have been observed in the climatic characteristics of Turkey. These changes showing compatibility with the general trend of global climate change, are felt in West Black Sea Basin. One of the biggest impacts of global climate change occurs on precipitation; while this situation causes drought in some regions due to low rainfall, in some areas, it makes an appearance in the form of flood and overflows as a result of extreme precipitation. In this study the effects of climate change in the Western Black Sea Basin was investigated by Innovative Sen Method. Innovation Sen Method was applied to precipitation data from meteorological stations located in this basin. These precipitation data were taken from the General Directorate of Meteorology Affairs. As a result of the study, some stations have not seen trends, while some stations have seen decreasing trends. The result of this declining trend is that rainfall will decrease in the future.
\end{abstract}

Keywords: Rainfall, Climate Change, West Black Sea Basin, Innovation Sen Method

\section{GİRIŞ}

İklim değişikliği, çevre ile ilgili 20. Yüzyılın ortalarında başlayan çevresel uyanışın bir sonucu olarak, bilim insanlarınca uzun süreden beri irdelenen bir konudur [1]. Hükümetlerarası İklim Değişimi Paneli (IPCC) Beşinci Değerlendirme Raporuna göre 20. yüzyılın ortalarından itibaren atmosferde meydana gelen 1sınmanın büyük bir bölümü insan faaliyetlerine dayalı olarak sera gazı konsantrasyonlarında gözlenen artıştan kaynaklanmıştır. Bunun neticesi olarak küresel sıcaklık son 150 yıl içerisinde yaklaşı $0,89^{\circ} \mathrm{C}$ yükselmiş ve yükselmeye de devam etmektedir [2, 3]. Bilim adamlarının modern klimatik kayıtların başlangıcı olarak tanımladıkları 1880 yılından itibaren küresel sıcaklıkların önemli oranda değiştiğini ifade etmektedirler (Şekil 1) [4,5].

Türkiye iklim değişikliğinin pek çok farklı yüzüyle karşı karşıya kalmaktadır. Ani ve çok şiddetli yağışlar, taşkınlar, kuraklık ve aşırı sıcaklık bu tehditlerden sadece iklim ve çevre üzerinde görülenlerden bazılarıdır. İklim değişikliğinin yıkıcı etkilerini ötelemek ve iklim değişikliği ile mücadele edebilmek için mevcut durumun tüm yönleriyle ele alınıp kavranması gerekmektedir [1, 6, 7].

*1Sorumlu yazar: Sakarya Üniversitesi, Teknoloji Fakültesi, İnşaat Mühendisliği Bölümü, 54187, Sakarya, Türkiye, gceribasi@sakarya.edu.tr 
Dolayısıyla bu çalışmada, iklim değişikliğinin Batı Karadeniz Havzasında etkisi yenilikçi şen yöntemi ile araştırılmıştır. Yenilikçi Şen Yöntemi, bu havzada bulunan meteorolojik istasyonlardan alınan yağış verilerine uygulanmıştır. $\mathrm{Bu}$ yağış verileri Devlet Meteoroloji İşleri Genel Müdürlüğünden alınmıştır.

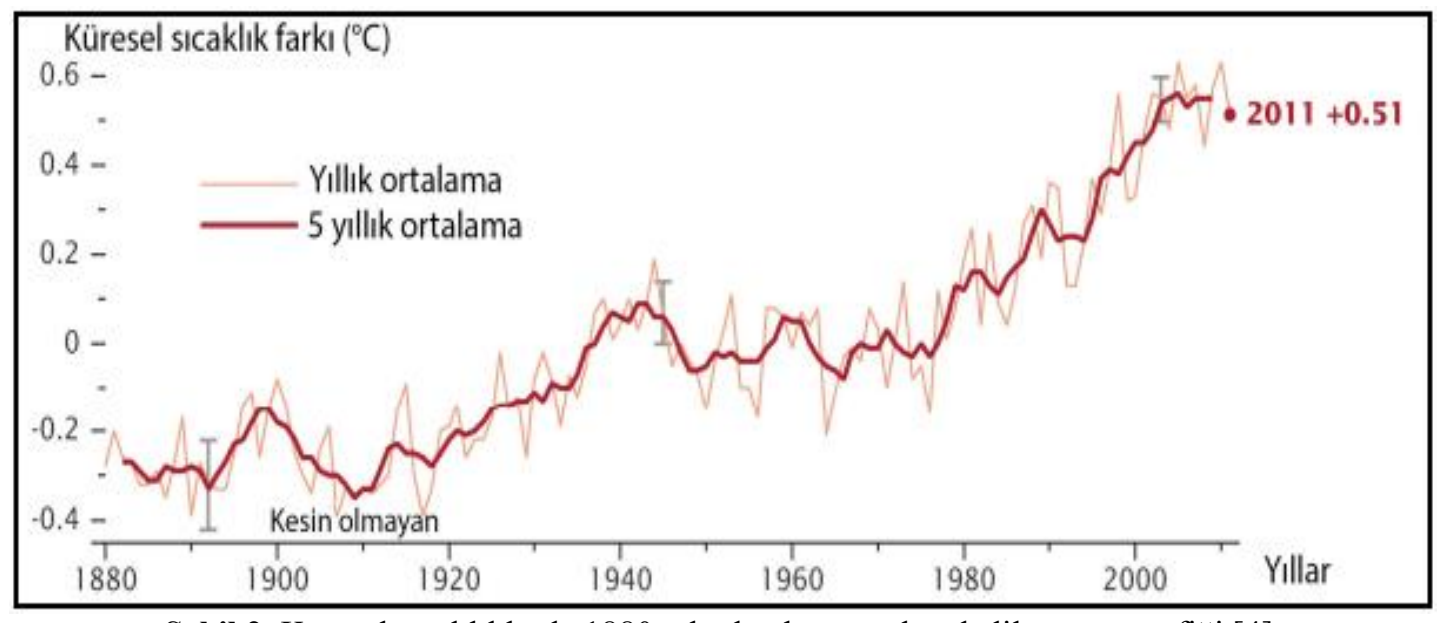

Şekil 2. Küresel sıcaklıklarda 1880 yılından bu yana kaydedilen artış grafiği [4].

\section{MATERYAL VE METOT}

\section{1. Çalıșma Alanı}

Batı Karadeniz Havzası yer şekilleri incelendiğinde, Batı Karadeniz'de birbirine paralel 3 sıra halinde uzanan dağlar, Orta Karadeniz'de kıyıdan uzaklaşıp, tek sıra halinde uzanır. Havza toplam olarak 2.896.766 hektar alanı kaplamakta olup, Türkiye genel yüzölçümünün \%1'ini teşkil etmektedir [2, 8, 9]. Batı Karadeniz Havzası'nda irili ufaklı çok sayıda yüzeysel su kaynağı bulunmaktadır. Bu su kaynaklarının en önemlilerinden biri Benli Dağ'dan doğan ve toplam uzunluğu 360 km'yi bulan Filyos Çayı'dır. Batı Karadeniz Havzası'nın toplam yağış alanı 29.682 $\mathrm{km}^{2}$ 'dir.Yıllık ortalama yağış yüksekliği $811 \mathrm{~mm}$ 'dir.
Ortalama yıllık akış $9,93 \mathrm{~km}^{3}$ olup ortalama havza verimi $10,6 \mathrm{l} / \mathrm{sn} / \mathrm{km}^{2} \operatorname{dir}[2]$.

Batı Karedeniz Havzası için 2015-2100 döneminde yapılmış olan iklim değişikliği projeksiyonlarına göre ortalama sıcaklıklarda sürekli bir artış olması beklenmektedir. 1971-2000 yılları gözlem verilerine göre ortalaması $11,6{ }^{\circ} \mathrm{C}$ olan havza geneli ortalama sicaklığında, 2071-2100 döneminde en az $1,6{ }^{\circ} \mathrm{C}$, en fazla $4,7{ }^{\circ} \mathrm{C}$ civarında artış yaşanması beklenmektedir. Ayrıca, İklim değişikliğinin etkisi ile 2015-2020 döneminde havzanın brüt su potansiyelinde \%50'lere varan azalma meydana gelebileceği öngörülmektedir [2]. Şekil 1'de Batı Karedeniz Havzası'nın haritası gösterilmektedir.

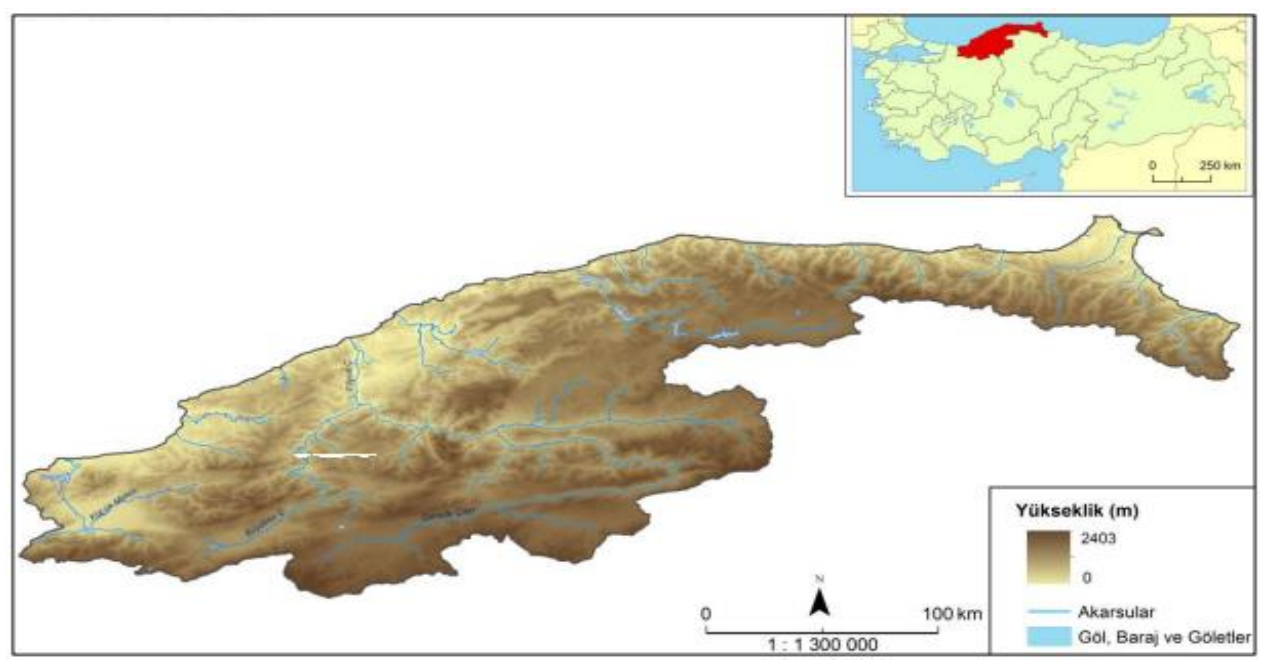

Şekil 1. Batı Karedeniz Havzası'nın haritası [2].

Devlet Meteoroloji Müdürlüğü'nün Batı Karadeniz Havzasındaki yağış istasyonlarında alınan verilerden Bartın istasyonu yağış gidiş grafiği şekil 2(a), Zonguldak istasyonu şekil 2(b), İnebolu istasyonu şekil 2(c), Sinop istasyonu şekil 2(ç), Bolu istasyonu şekil 2(d), Düzce istasyonu şekil 2(e), Amasra istasyonu şekil 2(f), Bozkurt

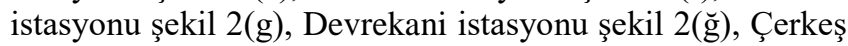
istasyonu şekil 2(h),'de verilmiştir. 


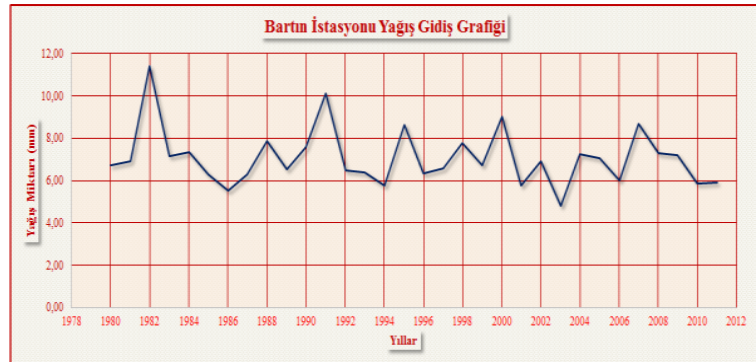

(a)

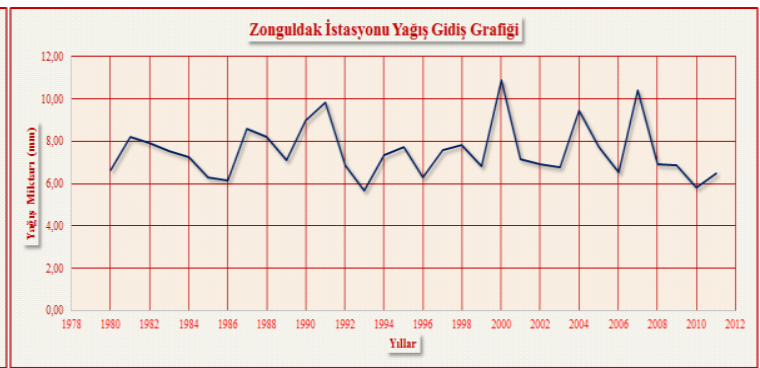

(b)

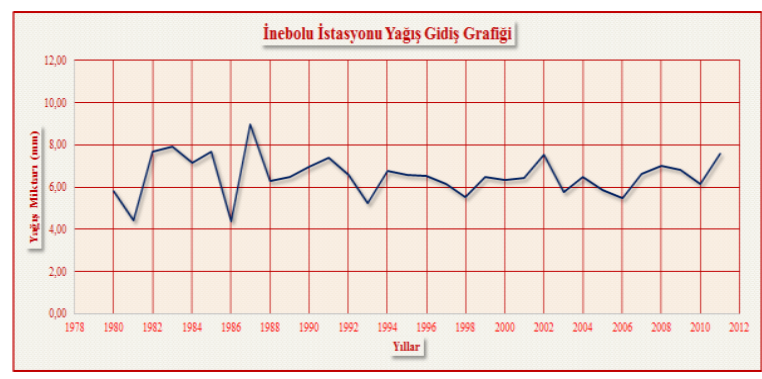

(c)

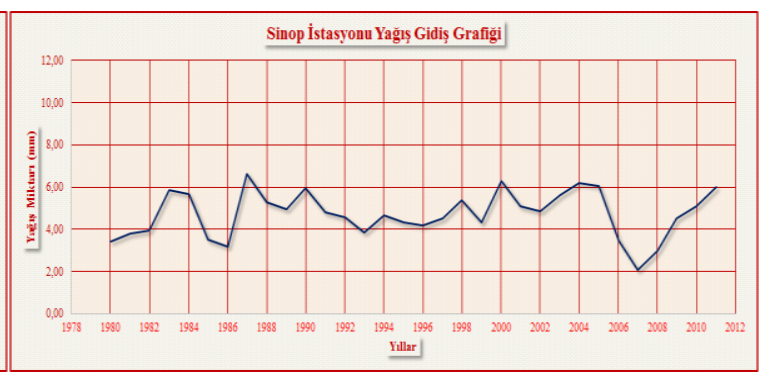

(ç)

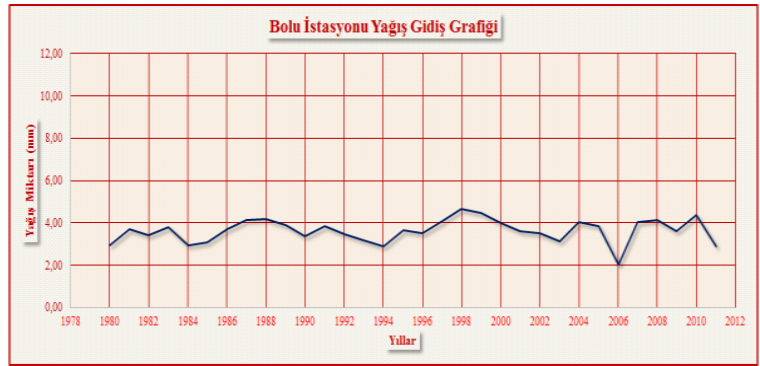

(d)

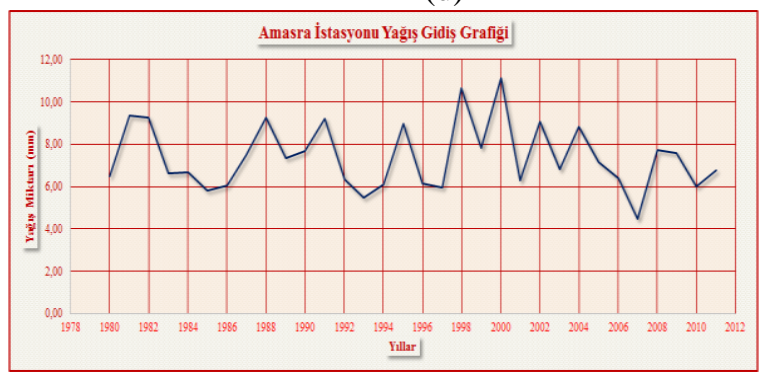

(f)

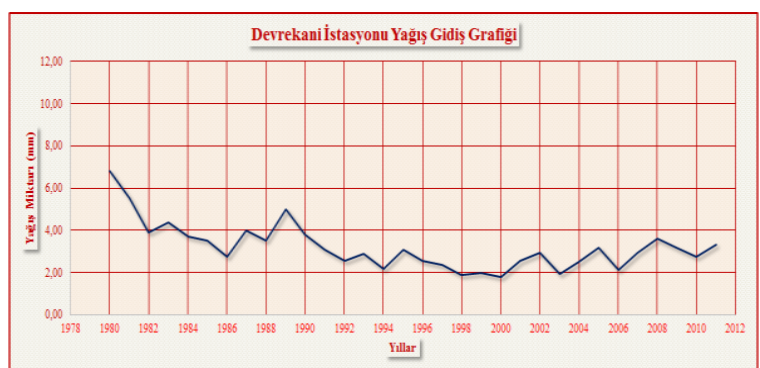

$(\breve{\mathrm{g}})$

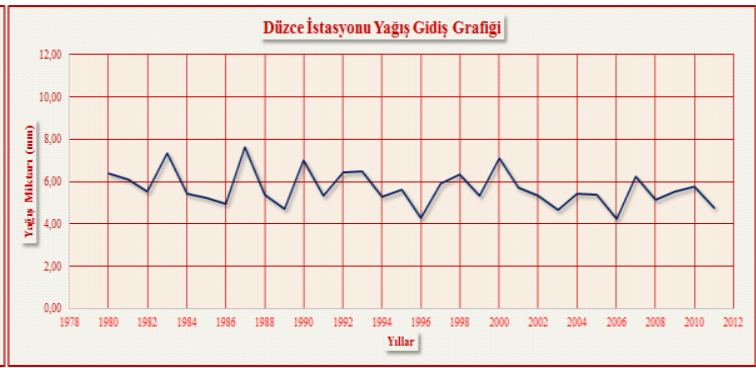

(e)

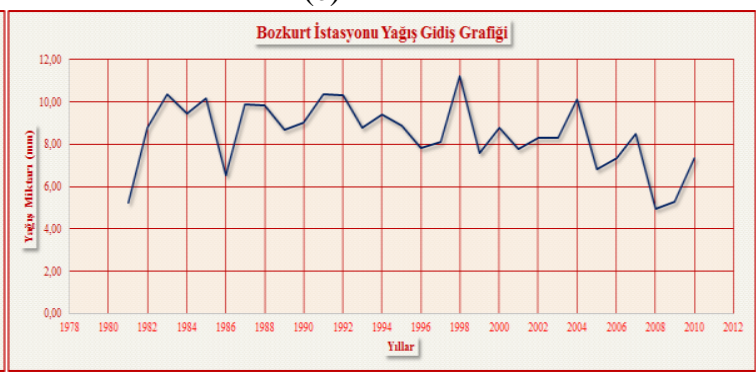

(g)

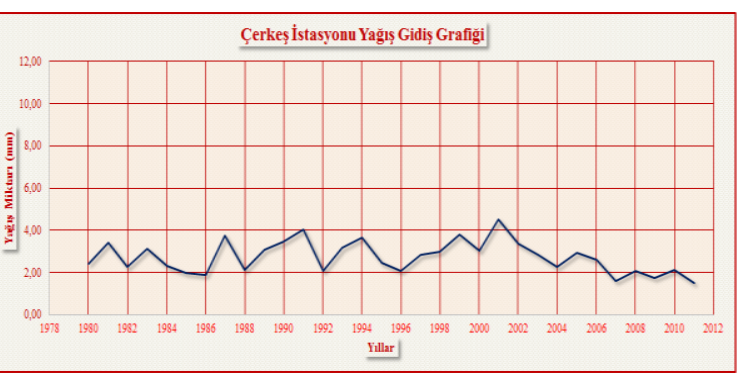

(h)

Şekil 2. Batı Karadeniz Havzasındaki yağış istasyonlarından alınan verilerin gidiş Grafikleri. 


\subsection{Yenilikçi Şen Yöntemi}

$\mathrm{Bu}$ yöntemde mevcut veri serisi ortadan iki eşit yarıya ayrılır. Her iki alt-seri ayrı ayrı küçükten büyüğe doğru sıralanır. Sonrasında ilk alt-seri (Xi) X-ekseni üzerinde ve ikinci alt seri $(\mathrm{Xj})$ Y-ekseni üzerinde yer almak üzere Kartezyen koordinat sistemi üzerinde sıralanır (Şekil 3). Eğer veri 1:1 doğrusunun üzerinde sıralanıyorsa trend yok demektir. Eğer veriler 1:1 doğrusunun alt üçgen alanda yer alıyor ise azalan bir trend olduğu; üst üçgen alanda yer alıyorsa, artan bir trend olduğu sonucuna varılır [10-17].

Şen'in yönteminin yenilikçi özelliği tüm data aralıklarında yorumlanabilmesidir. Bu metot, Şen tarafindan (2013) Merkez/Bursa, Uludağ/Bursa, Firat Nehri üzerinde uygulanmıştır. Aynı metot, yine Şen tarafından (2012) Aslantas Baraj1, Menzelet Baraj1 ve Cizre istasyonunda uygulanmıştır. Son olarak da Göztepe, Florya, Edirne, Bolu ve Bursa lokasyonlarındaki kaydedilmiş uzun dönemli sıcaklık verilerinin üzerinde uygulanmıştır [10].

\section{BULGULAR VE DEĞERLENDIRME}

Devlet Meteoroloji Müdürlüğü'nün Batı Karadeniz Havzasındaki yağış istasyonlarında alınan verilerine yenilikçi şen yöntemi uygulanmış ve analiz sonuçları Bartın istasyonu şekil 4(a), Zonguldak istasyonu şekil 4(b),

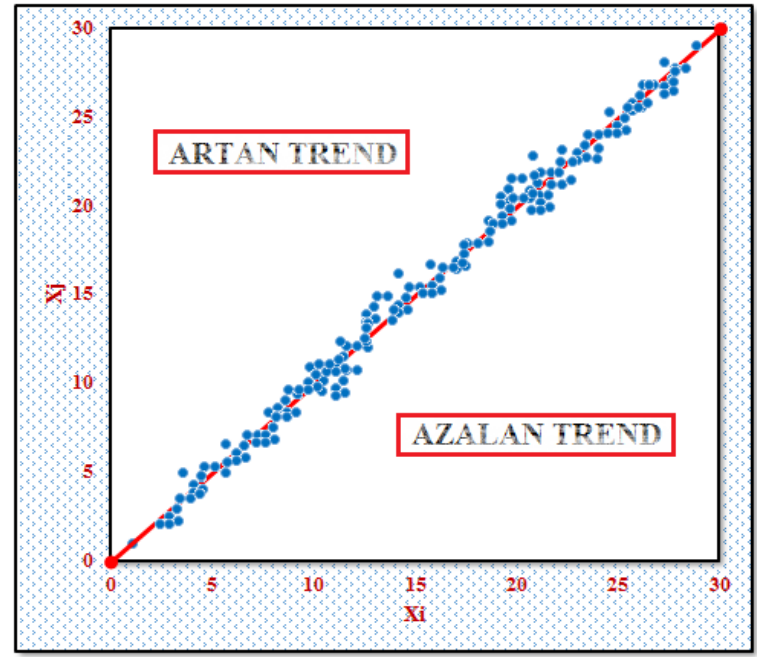

Şekil 3. Şen Yöntemi Sonucunu Gösteren Grafik.

İnebolu istasyonu şekil 4(c), Sinop istasyonu şekil 4(ç), Bolu istasyonu şekil 4(d), Düzce istasyonu şekil 4(e), Amasra istasyonu şekil 4(f), Bozkurt istasyonu şekil 4(g),

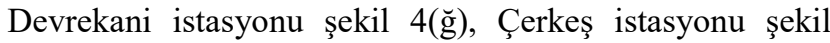
4(h), 'de verilmiştir.

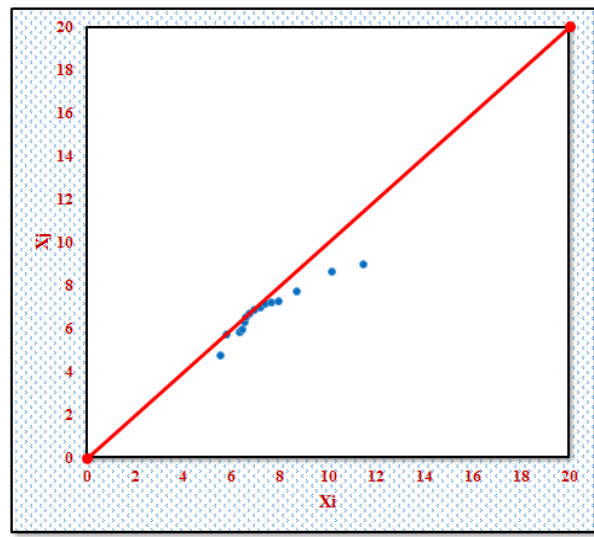

(a)

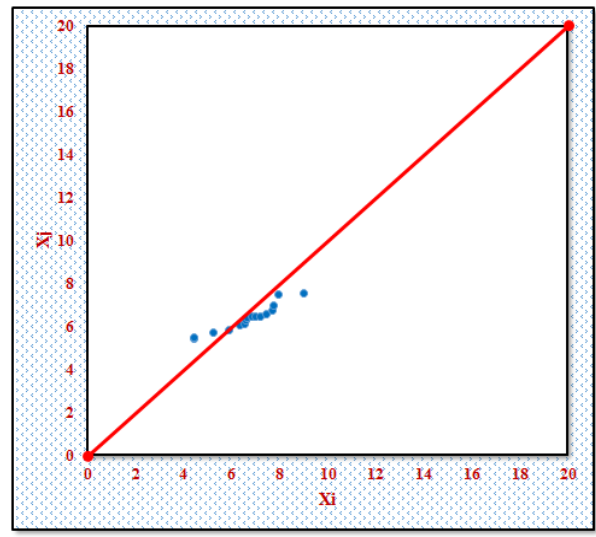

(c)

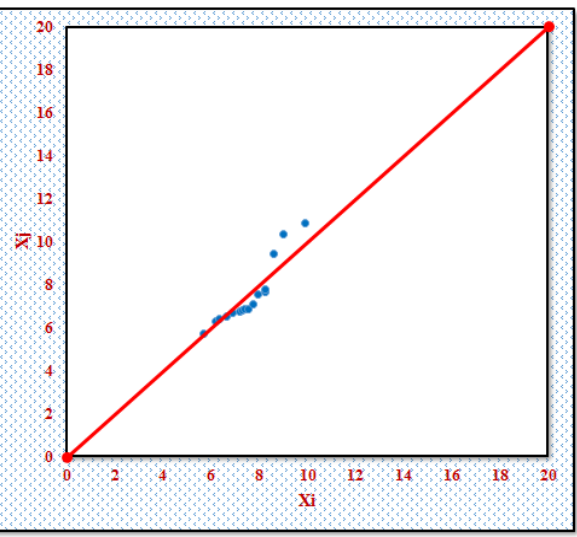

(b)

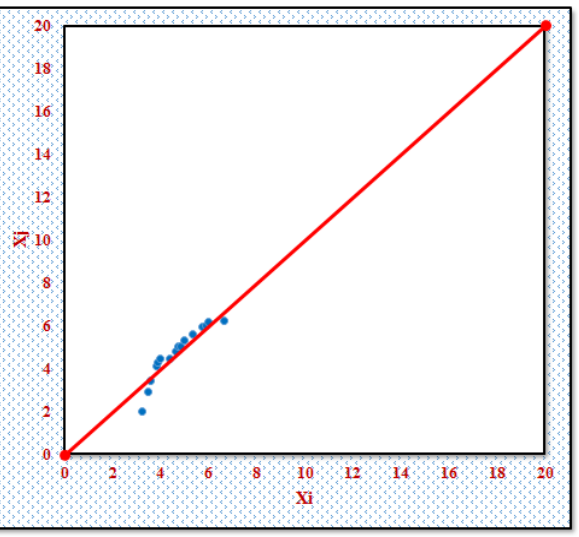

(ç) 


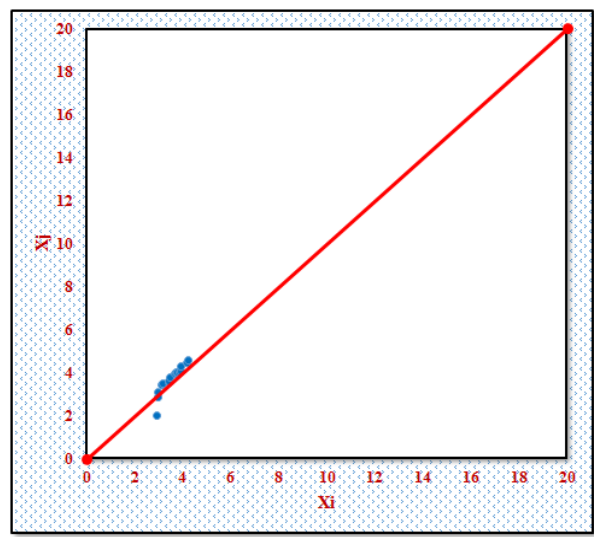

(d)

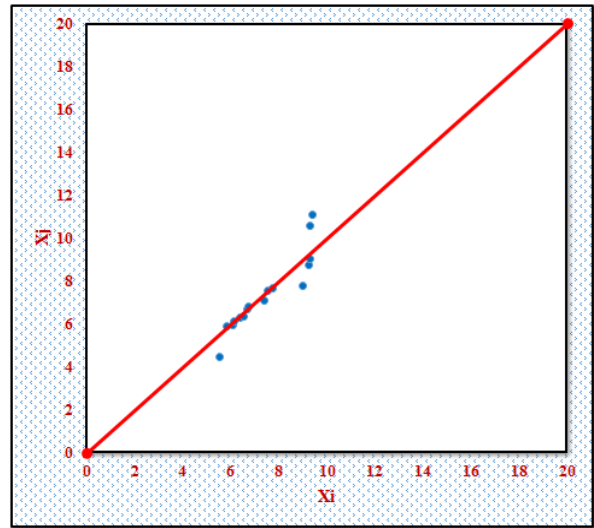

(f)

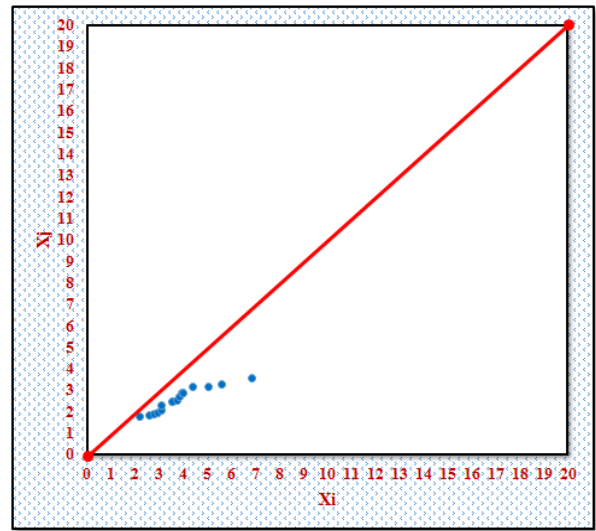

$(\breve{\mathrm{g}})$

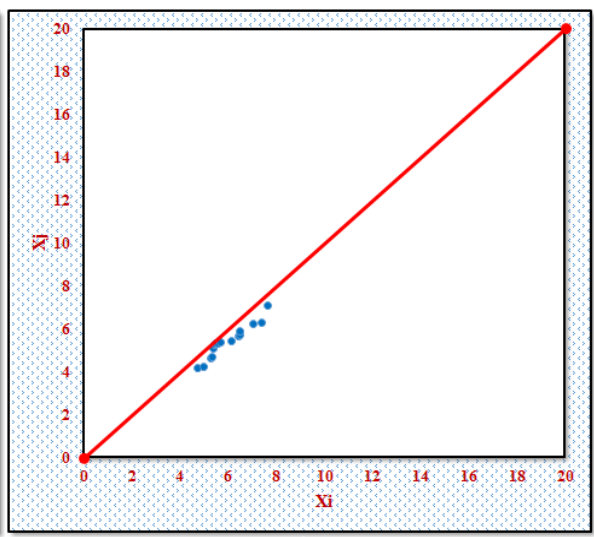

(e)

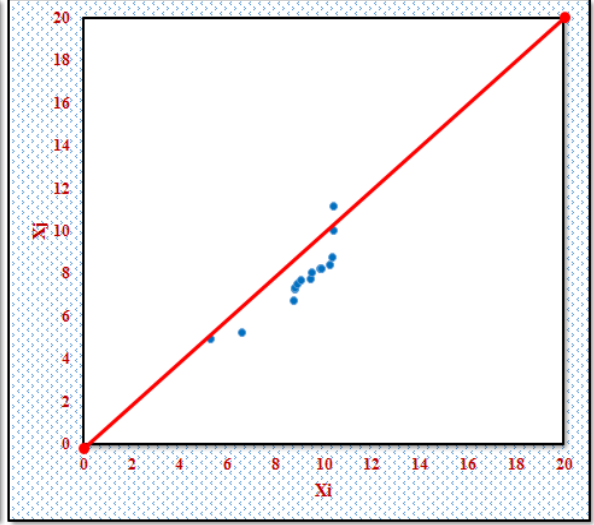

(g)

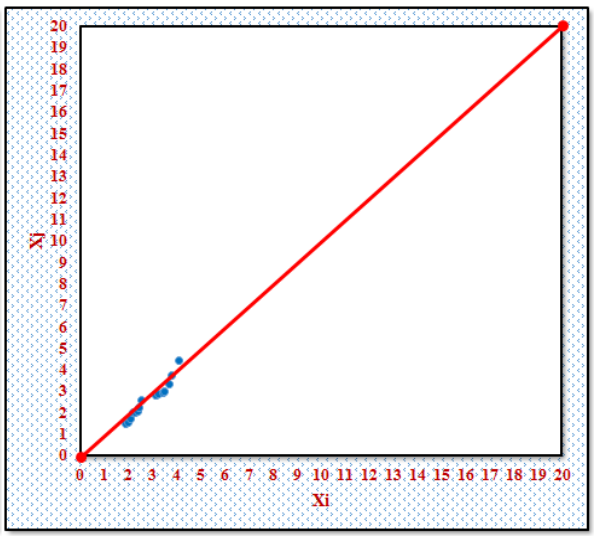

(h)

Şekil 4. Batı Karadeniz Havzasının Yağış Verilerinin Şen Yöntemi İle Analiz Sonuçları.

Şekil 4'e bakıldığında Bartın istasyonun yağış verilerinde azalan trend görülmektedir. Yine aynı şekilde Bozkurt ve Devrekani istasyonlarının yağış verilerinde azalan trend görülmektedir. Sinop istasyonun yağış verilerinde de az da olsa azalan trend görülmektedir.

Zonguldak, İnebolu, Bolu, Düzce ve Çerkeş istasyonlarının yağış verilerinde anlamlı bir trende rastlanmamıştır. Amasra istasyonun yağış verilerinde ise az da olsa artan trend varlığı söylenebilir.

\section{SONUÇLAR}

Küresel iklim değişikliğinin en büyük etkilerinden biri yağışlar üzerinde meydana gelip; bu durum bazı bölgelerde yağış azlığı nedeniyle kuraklığa neden olurken; bazı bölgelerde ise ekstrem yağışlar sonucu sel ve taşkınlar şeklinde kendini göstermektedir. Bu çalışmada da iklim değişikliğinin Batı Karadeniz Havzasında etkisi yenilikçi şen yöntemi ile araştırılmıştır. Bu yöntem, havzanın yağış verilerine uygulanmıştır. $\mathrm{Bu}$ yağış verileri Devlet Meteoroloji İşleri Genel Müdürlüğünden alınmıştır. 
Yapılan çalışma sonucunda, 4 istasyonda azalan trendlergörülürken 5 istasyonda trend görülmemiştir. 1 istasyonda ise artan trende rastlanmıştır. Genel olarak azalan trend sonucu ileride yağışların azalacağı aynı zamanda sıcaklıkların artacağı dolaysıyla mevcut su kaynaklarının bu durumdan etkileneceği sonucunu ortaya koyabilir. $\mathrm{Bu}$ durumun önüne geçebilmek için alınacak önlemler sıralanacak olursa;

- Özellikle bütüncül su yönetim anlayışının benimsenip geliştirilmesi gerekir.

- İklim değişikliği etkisiyle meydana gelecek zararları azaltmak için planlamalar yapılmalıdır.

- Sicaklıkların artmasıyla buharlaşmanın gelecekte çok daha fazla artacağının farkında bulunarak yüzeysel su kaynaklarının azalacağı beklentisi su yapıları tasarımında dikkate alınmalıdır.

- Su kaynakları yönetim planlamasında, bu çalışma kapsamında elde edilen sonuçlar göz önünde tutulmalıdır.

- Havza ölçeğinde iklim değişikliği etkilerinin belirlenip havza yönetim planlarına kuraklık analizi ile birlikte dâhil edilmelidir.

- Suyun geri dönüşümüne önem verilip su tasarrufu teşvik edilmelidir.

- İklim değişikliğinin olumsuz etkilerinin sadece yağışlarda olmayacağının farkına varılıp, sosyokültürel alanda, enerji sektöründe, tarımda, ekonomide ve sağlık alanlarında etkileri ve doğuracağı sonuçlar bilimsel yöntemlerle ortaya konulup kamuoyu bilinçlendirilmelidir [7].

\section{KAYNAKLAR}

[1]. M. E. Büken, “Adana İlinde İklim Değişikliği Etkileri Değerlendirmesi”, Çukurova Üniversitesi, Fen Bilimleri Enstitüsü, Çevre Mühendisliği Anabilim Dalı, Yüksek Lisans Tezi, Adana, 2016.

[2]. T.C. Orman ve Su İşleri Bakanlığg Su Yönetimi Genel Müdürlüğü, "İklim Değişikliğinin Su Kaynaklarına Etkisi Projesi”, Proje Nihai Raporu, EK 15-Batı Karadeniz Havzas1, 2016.

[3]. Intergovernmental Panel on Climate Change (IPCC) AR5-Fifth Assessment Report, Cambridge: Cambridge University Press, 2014.

[4]. H. Turoğlu, "İklim Değişikliği ve Bartın Çayı Havza Yönetimi Muhtemel Sorunları”, Coğrafi Bilimler Dergisi, Say1 12, Syf. 1-22, 2014.

[5]. J. E. Hansen, "NASA Finds 2011 Ninth Warmest Year on Record", Data source: NASA Goddard Institute for Space Studies, Image credit: NASA Earth Observatory (http://www.giss.nasa.gov/research/news/20120119/, 10.05.
2013), 2012.

[6]. E. Biberoğlu, "Küresel İklim Modellerinin Yağış ve Sıcaklık Tahminlerinin İstatistiksel Ölçek İndirgemesi", Dokuz Eylül Üniversitesi, Fen Bilimleri Enstitüsü, İnşaat Mühendisliği Anabilim Dalı, Doktora Tezi, İzmir, 2017.

[7]. İ. Dabanl1, "Türkiye'de İklim Değişikliğinin YağışSıcaklığa Etkisi ve Kuraklık Analizi: Akarçay Örneği”, İstanbul Teknik Üniversitesi, Fen Bilimleri Enstitüsü, İnşaat Mühendisliği Anabilim Dalı, Doktora Tezi, İstanbul, 2017.

[8]. Su Yönetimi Genel Müdürlüğü (SYGM) Bilgi İşlem Daire Başkanlığı'ndan Temin Edilen Veriler, 2013.

[9]. G. Çeribaşı, "Karadeniz ve Sakarya Havzalarında Yağış-Akış-Askıda Katı Madde Verilerinin Trend Analizi İle İncelenmesi”, Sakarya Üniversitesi, Fen Bilimleri Enstitüsü, İnşaat Mühendisliği Anabilim Dalı, Doktora Tezi, Sakarya, 2015.

[10]. G. Ceribasi and E. Dogan, "Application of Trend Analysis Method on Rainfall-Stream Flow-Suspended Load Datas of West and East Black Sea Basins and Sakarya Basin", Fresenius Environmental Bulletin, Vol. 25, Number 1, pp. 300 - 306, 2016.

[11]. G. Çeribaşı ve E. Doğan "Trend Analizi Yöntemi Kullanılarak Batı ve Doğu Karadeniz İle Sakarya Havzası Akım Miktarlarının Değerlendirilmesi”, Suleyman Demirel University (SDU) International Journal of Technologic Science, Vol. 7, Number 2, pp. 1-12, 2015.

[12]. Z. Sen, "Innovative Trend Analysis Methodology", Journal of Hydrological Engineering, Vol. 17, pp. 10421046, 2012.

[13]. Z. Sen, "Trend Identification Simulation and Application", Journal of Hydrological Engineering, Vol. 19, 2013.

[14]. A. Yıldırım, "Trend Analizi Yöntemleri: Orta Fırat Havzası Uygulaması”, İstanbul Teknik Üniversitesi, Enerji Enstitüsü, Enerji Bilim ve Teknoloji Anabilim Dalı, Yüksek Lisans Tezi, İstanbul, Türkiye, 2015.

[15]. G. Ceribasi, "Analyzing of Meteorological and Hydrological Datas of Iznik Lake Basin by Using The Innovative Sen Method", Journal of Environmental Protection and Ecology, Vol. 19, Number 1, pp. 15-24, 2018.

[16]. G. Çeribaşı, “Türkiye'deki Bazı Akarsuların Taşıdıkları Sediment (Katı Madde) Miktarlarının Şen Yöntemi İle Analizi”, Yapı Dünyası Dergisi, Sayı 258-259, syf. 43-47, 2017.

[17]. G. Çeribaşı, U. Aytulun ve M. Özdin, "Yenilikçi Şen Yöntemi İle Sakarya Nehrinin Akım Miktarlarının ve Sakarya Bölgesinin Yağış Miktarlarının Analizi”, 1st International Advanced Researches and Engineering Congress, 16-18 Kasım 2017, Osmaniye, Türkiye. 